\title{
U14, U16 Futbol Takımlarının Bir Futbol Sezonundaki Bazı Fizyolojik ve \\ Motorik Özeliklerinin Ölçülmesi
}

\author{
Bilal YAVAŞ ${ }^{1 *}$ (D) \\ Hasan AKKUŞ² \\ ${ }^{1}$ Gençlik ve Spor İl Müdürlüğü, KONYA \\ ${ }^{2}$ Selçuk Üniversitesi Spor Bilimleri Fakültesi, KONYA
}

\section{DOI: 10.31680/gaunjss.943769}

Orijinal Makale / Original Article

Geliş Tarihi / Received: 27.05.2021
Kabul Tarihi / Accepted: 16.06 .2021

Yayın Tarihi / Published: 21.06.2021

\section{Öz}

Bu araştırmanın amacı, Konyaspor ve Anadolu Selçuklu spor kulüplerinde oynayan U14 ve U16 takımlarının bir yıl sergiledikleri performanslarının karşılaştırmalı olarak değerlendirilmesidir. Yarı denem modeliyle gerçekleştirilen araştırmada Konyaspor ve Anadolu Selçuklu Spor Kulübü U14 ve U16 takımlarında oynayan sporculardan 20 erkek sporcu seçilerek toplamda 85 sporcu bu çalışma için gönüllü olmuştur. Tüm takımlarda ön test ve son test boy (cm), kilo (kg), biceps, trıceps, subscapular, supraılıac, sırt kuvveti, bacak kuvveti, pençe kuvveti, $30 \mathrm{M}$ sürat (Sn), MaxVO2 ve mesafe ölçümleri eş zamanlı olarak gerçekleştirilmiştir. Araştırmada her bir takım için ayrı ayrı ölçümleri hesaplanan ortalama ve standart sapmaları ile ön test ve son test değerleri üzerinde gerçekleştirilen t testi değerlerine yer verilmiştir. Bir yıl boyunca devam eden antrenmanlarda ölçümleri kayıt altına alınmıştır. Yapılan ölçümlerin normal dağılıma uygunluğu Shapiro Wilk testi ile incelenmiştir. Bu yönüyle, Konyaspor ve Anadolu Selçuklu U14-U16 takım sporcuların ölçümlerinde parametrik analiz tekniklerinin kullanılmasına karar verilmiştir. Bu kapsam tüm takımların ön test-son test ölçümlerinin karşılaştırımasında bağımlı örneklem t Testi; diğer taraftan Konya Spor ve Anadolu Selçuklu Spor Takımları arasındaki karşılaştırmalarda da Bağımsız Örneklem t Testi Teknikleri kullanılmıştır. Gerçekleştirilen son test ölçümlerinde Konyaspor ve Anadolu Selçuklu U14-U16 spor takımlarında bulunan sporcuların kilo, bacak kuvveti, subscapular, MaxVO2 ve mesafe ölçümleri arasında istatistiksel olarak anlamlı farklılık bulunurken $(p<0,05)$. Boy, biceps, triceps, suprailiak, sırt kuvveti, pençe kuvveti ve $30 \mathrm{mt}$ sürat ölçümlerinde anlamlı bir fark bulunamamıştır $(p>0,05)$. Son test ölçümlerin ortalamalarına göre Konyasporlu futbolcuların Anadolu Selçuklu Spor takımında oynayan akranlarına kıyasla daha yüksek kilo, subscapular, bacak kuvveti ve maxVO2 ölçümleri elde ettikleri görülmüştür.

Anahtar Kelimeler: Futbol; spor; test, U14, U16.

\section{Measurement of Some Physiological and Motoric Characteristics of U14, U16}

\section{Soccer Teams in a Soccer Season}

\begin{abstract}
The purpose of this research is to comparatively evaluate the performances of U14 and U16 teams playing in Konyaspor and Anadolu Selçuklu Sports clubs for one year. In the research conducted with the semi-denem model, 20 male athletes were selected from the athletes playing in Konyaspor and Anadolu Selçuklu Sports Club U14 and U16 teams, and a total of 85 athletes volunteered for this study. In all teams pretest and posttest measurements of height $(\mathrm{cm})$, weight $(\mathrm{kg})$, biceps, triceps, subscapular, suprailiac, back strength, leg strength, claw strength, $30 \mathrm{M}$ sprint (Sec), MaxVO2 and distance were carried out simultaneously. In the study, the mean and standard deviations, which were calculated separately for each team, and the t-test values performed on the pre-test and post-test values were included. The measurements were recorded in the trainings that lasted for a year. The conformity of the measurements to the normal distribution was examined with the Shapiro Wilk test. In this regard, it was decided to use parametric analysis techniques in the measurements of Konyaspor and Anatolian Selçuklu U14-U16 team athletes. In this context, Dependent Sample t-Test was used to compare the pretest-posttest measurements of all teams; on the other hand, Independent Sample t-Test techniques were used in the comparisons between Konyaspor and Anadolu Selçuklu Sports Teams. While there was a statistically significant difference between the weight, leg strength, subscapular, MaxVO2 and distance measurements in the post-test measurements of the athletes in the Konyaspor and Anadolu Selçuklu Spor U14-U16 teams $(p<0,05)$; no significant difference was found in height, biceps, triceps, suprailiac, back strength, claw strength and $30 \mathrm{mt}$ speed measurements $(p>0,05)$. According to the averages of the post-test measurements, it was seen that Konyaspor football players achieved higher weight, subscapular, leg strength and maxVO2 measurements compared to their peers playing in Anadolu Selçuklu Sports Team.
\end{abstract}

Keywords: Soccer, sport, test, U14, U16. 


\section{Giriş}

Futbolun üst düzey dayanıklılık, kuvvet, sürat ve çabukluk gibi sportif performans ve kontrol gerektiren bir takım ve temas sporu olması, günümüzde kaleci dâhil bütün mevkilerdeki oyuncuların her türlü motorik özelliklere sahip olmasını gerektirmektedir. Bu nedenle sporcunun performansının artırılması için öncelikle futbolcunun fizyolojik profilinin saptanması gerekir (Koç 2010).

Sporda başarılı olmak, başarıyı devam ettirmek, kişinin fiziksel, psikolojik ve sosyal spor alanlarının seçilmesi ve spora erken yaşlarda başlanması, doğru antrenman metotlarının uygulanması, fiziksel, duygusal, fizyolojik ve sosyal bileşenlerinin iyi düşünülmesi gerekir. Bunun yanında uygun testlerin yapılması ve sonuçların iyi değerlendirilmesi önemlidir (Kılıç 2007).

Günümüz futbolunun eskiye oranla daha hızlı oynanması ve fiziksel gücün bu hız içerisinde hiçbir zaman önemini yitirmeyip aksine futbolun en önemli parçalarından biri olarak kalması, alt yapıdaki çocukların bu yöndeki eğitimlerinin ne kadar önemli olduğunu da ortaya koymuştur (Taşkın 2015) .

Bu çalışmada U14, U16 futbol takımlarının bir futbol sezonundaki bazı fizyolojik ve motorik özelliklerinin ölçülmesi amaçlanmıştır.

\section{Yöntem}

\section{Çalışma Grubu ve Deney Dizaynı}

Çalışmaya Anadolu Selçuklu Spor ve Konyaspor U14 ve U16 futbol takımlarında spor yapan 14-16 yaş aralığında 85 futbolcu katılmıştır. Araştırma gruplarına atanan 85 futbolcunun 2 yıl ve daha fazla süredir futbol oynayan sporculardan oluşturulmuştur. Araştırma grubunda Konya Spor U14-U16 takımlarından 40 futbolcu Anadolu Selçuklu Spor takımından ise 45 futbolcu çalışma grubunda yer almıştır. Yaş dağılımı açısından araştırma gruplarına bakıldığında Anadolu Selçuklu U16 takımında 26 futbolcu, Konya Spor U16 takımında 22 sporcu, Anadolu Selçuklu Spor U14 takımında 19 futbolcu ve Konyaspor U14 takımında ise 18 futbolcu yer almaktadır. Takımlarında aktif olarak spor yapan tüm futbolcular araştırma gruplarına alınmıştır.

Konyaspor ve Anadolu Selçuklu Spor U14 - U16 futbol takımlarının 2017-2018 futbol sezonundaki bazı fizyolojik ve motorik özeliklerinin karşılaştırmalı olarak incelendiği bu çalışmada yarı deneme modellerinden kontrol gruplu ön test-son test 
deseni ile araştırma yürütülmüştür. Ön test ve son testler bir sezon boyunca müsabakalardan önce ve sonra alınmıştır.

\section{Verilerin Toplanması}

\section{Boy ölçümü}

Çalışmaya katılan futbolcuların boy uzunlukları, $0,01 \mathrm{~cm}$ hassasiyetli olan uzunluk ölçeği ile ölçülmüştür. Boy uzunluğu; çıplak ayakla, anatomik duruşta, ayaklar yere düz basılı, nefesini tutulmuş, topuklar birleşik, baş üstü tablası verteks noktasına değecek şekilde ve baş frontal düzlemde pozisyon aldıktan sonra ölçülmüştür. Ölçüm değerleri cm cinsinden kaydedilmiştir.

\section{Kilo ölçümü}

Tüm futbolcuların vücut ağırlıkları aynı ölçme aracı kullanılarak gerçekleştirilmiştir. Vücut ağırlıkları ölçümünde King marka \%99 hassasiyetle ölçüm yapan elektronik tartı aleti kullanılmıştır. Ağırlık ölçümlerinde futbolcular üzerinde ağırlık yapmayacak şort ve tişörtlerle çıplak ayaklı bir şekilde işlemler gerçekleştirilmiştir. Ağırlık ölçümleri kg cinsinden kaydedilmiştir.

\section{Vücut Yağ Yüzdesinin Ölçümü ve Hesaplanması}

Deri altı yağ ölçümü Skinfold Caliper ölçüm cihazı ile yapılmıştır. Başparmak ve işaret parmağı ile deri ve deri altı yağı tutularak, kas dokusundan uzağa çekilerek, aletin uç kısmı ile sert bir basınç uygulanarak yapılmıştır. Durnin and Womersley Formülü beden yoğunluk indeksini hesaplamak için kullanılmış bu amaç için biceps, triceps, subscapula, Suprailiak bölgelerinin skinfold deri altı yap kalınlıkları ölçülmüştür.

\section{Metre Sürat Testi}

$\mathrm{Bu}$ test için koşu pistinde 30 m'lik mesafenin başlangıç ve bitimine yerleştirilmiş fotoselli kronometre ile sporcuların bu mesafeyi koşma süreleri tek tek üç kez ölçülerek ve en iyi değerleri kaydedilmiştir.

\section{Sırt Kuvveti Ölçümü}

Sırt kuvveti ölçümünde sırt ve bacak dinamometresi (Takei marka) kullanılmıştır. Sporcuların dizleri gergin olarak dinamo sehpası üzerine ayaklarını yerleştirerek, kollar 
gergin, sırt düz, gövde hafif öne eğik, elleriyle kavradığı dinometreyi yukarı çekerek ölçüm yapılmıştır. Bu test dinlenilerek üç kez tekrar edilecek, en yüksek değer kaydedilmiştir.

\section{Bacak Kuvveti Ölçümü}

Bacak kuvveti ölçümünde sırt ve bacak dinamometresi kullanılmış ve sporcuların dizleri bükük vaziyette dinamo sehpasına ayaklarını yerleştirdikten sonra kollar gergin, sırt düz ve vücut hafif eğik iken kavradığı dinamometre barını yukarı çekerek ölçüm yapılmıştır. Bu test dinlenilerek üç kez tekrar edilecek, en yüksek değer kaydedilmiştir.

\section{Pençe Kuvvetinin Ölçümü}

Pençe kuvvetinin ölçümünde el dinamometresi (Takei marka) kullanılmıştır. Denek kol dirsekten gergin vaziyette, kolunu gövdesine dayamadan dinamometreyi maksimum eforla sıkacak ve skaladan görülen değer kaydedilmiştir. Üç denemenin en yükseği pençe kuvveti olarak kaydedilmiştir.

\section{0 m Mekik koşusu dayanıklılık Ölçüm Testi}

Denekler 20 mt.lik mesafeyi gidiş dönüş olarak koşmuştur. Test yavaş bir koşu hızında $(8 \mathrm{~km} / \mathrm{s})$ başlar ve denek duyduğu 1. sinyal sesinde koşusuna başlar. Başta yavaş olan hız her 10 sn bir giderek artar. 2. Sinyal sesine kadar çizgiye ulaşmak zorundadır. 2. Sinyal sesini duyduğunda ise tekrar geri dönerek başlangıç çizgisine döner ve bu koşu hızı her dakikada $0.5 \mathrm{~km} / \mathrm{s}$ artan sinyallerle devam eder. Denek sinyali duyduğunda ikinci sinyalde pistin diğer ucunda olacak şekilde temposunu ayarlar. Başta yavaş olan hız her 10 sn bir giderek artar. Denek bir sinyal sesini kaçırıp 2. sine yetişirse teste devam eder. Eğer denek iki sinyali üst üste kaçırırsa test sona erer. Deneğin en son koştuğu seviye ve turu test kâğıdına işlenir ve $\mathrm{VO}_{2 \max }$ hesaplanır.

Formül: V02 $\max =31.025+3.238 \times$ (sürat) $-3.248 \times$ (yaş) $+0.1536 \times$ (sürat) $x$ (yaş)

\section{Verilerin Analizi}

İstatistiksel analizler gerçekleştirilmeden önce boy ve kilo ölçümlerinde normal dağıım varsayımları test edilmiştir. Elde edilen verilerin normal dağılıma uygunluğu Shapiro Wilk testi ile değerlendirilmiştir $(p>0,05)$. Normallik dağılımı için basıklık çarpıklık durumuna da bakılmıştır. Bu yönüyle, Konyaspor ve Anadolu Selçuklu U14U16 takım sporcuların ölçümlerinde parametrik analiz tekniklerinin kullanılmasına karar verilmiştir. Bu kapsamda tüm takımların ön test-son test ölçümlerinin 
karşılaştııımasında bağımlı örneklem t Testi; diğer taraftan Konya Spor ve Anadolu Selçuklu Spor Takımları arasındaki karşılaştırmalarda da Bağımsız Örneklem t Testi Teknikleri kullanılmıştır.

\section{Bulgular}

Tablo 1. Takımların ayrı ayrı yaş, boy, kilo ön test-son test tanımlayıcı istatistikleri

\begin{tabular}{|c|c|c|c|c|c|c|}
\hline & \multicolumn{2}{|c|}{ Yaş } & \multicolumn{2}{|c|}{ Boy } & \multicolumn{2}{|l|}{ Kilo } \\
\hline Takı & $\begin{array}{c}\text { Ön test } \\
\text { Ort }\end{array}$ & $\begin{array}{c}\text { Son Test } \\
\text { Ort }\end{array}$ & 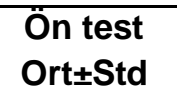 & $\begin{array}{c}\text { Son Test } \\
\text { Ort } \pm \text { Std }\end{array}$ & $\begin{array}{l}\text { Ön test } \\
\text { Ort+Std }\end{array}$ & $\begin{array}{c}\text { Son Test } \\
\text { Ort } \pm \text { Std }\end{array}$ \\
\hline U14 & 14,00 & 14,00 & $1,55 \pm 0,08$ & $1,66 \pm 0,33$ & $6,04 \pm 5,27$ & $45,72 \pm 7,59$ \\
\hline U16 Ana & 16,00 & 16,00 & $L, 73 \pm 0,07$ & $1,73 \pm 0,06$ & $62,50 \pm 6,19$ & $60,86 \pm 5,95$ \\
\hline Konya_S U14 & 14,00 & 14,00 & $1,59 \pm 0,09$ & $1,64 \pm 0,09$ & $47,63 \pm 4,70$ & $52,17 \pm 7,20$ \\
\hline Konya_S U16 & 16,00 & 16,00 & $1,73 \pm 0,05$ & $1,75 \pm 0,06$ & $69,24 \pm 4,01$ & $71,46 \pm 5,84$ \\
\hline
\end{tabular}

Tablo 2. Anadolu Selçuklu Spor Kulübündeki U14 takım sporcularının ön test-son test ölçümlerinin karşılaştırılması

\begin{tabular}{|c|c|c|c|c|c|c|}
\hline & \multicolumn{2}{|c|}{ Ön Test } & \multicolumn{2}{|c|}{ Son Test } & \multirow[b]{2}{*}{$\mathbf{T}$} & \multirow[b]{2}{*}{$\mathbf{P}$} \\
\hline & Ortalama & Ss & Ortalama & Ss & & \\
\hline Biceps & 5,86 & 1,52 & 5,05 & 1,96 & 2,271 & ,036* \\
\hline Triceps & 9,93 & 2,79 & 9,65 & 3,19 & ,863 & ,400 \\
\hline Subscapular & 7,79 & 1,97 & 7,23 & 2,01 & 1,575 & 133 \\
\hline Suprailiak & 6,72 & 3,04 & 7,06 & 3,33 &,- 836 & 414 \\
\hline Sırt Kuvveti & 49,87 & 12,33 & 46,14 & 14,41 & 1,365 & 189 \\
\hline Bacak Kuvveti & 29,55 & 6,29 & 26,92 & 4,95 & 1,807 & ,088 \\
\hline Pençe Kuvveti & 21,99 & 6,22 & 39,24 & 71,12 & $-1,073$ & ,298 \\
\hline 30 M Sürat (Sn) & 5,09 & 0,35 & 5,10 & 0,31 &,- 120 & ,906 \\
\hline MaxVO2 & 44,32 & 4,44 & 44,17 & 4,71 & ,254 & ,803 \\
\hline Mesafe & 1095,79 & 195,00 & 1146,32 & 252,02 & $-1,013$ & ,325 \\
\hline
\end{tabular}
$\left({ }^{*} p<0,05\right)$

Tablo 2'ye göre yapılan analiz sonucunda Anadolu Selçuklu Spor Kulübünde oynayan U14 Takımı futbolcularının ön test-son test ölçümleri üzerinde gerçekleştirilen bağımlı örneklem $t$ testi sonuçları görülmektedir. Analizlere göre Anadolu Selçuklu Spor Kulübü U14 futbolcularının sadece biceps ön test-son test ölçümlerinde hesaplanan $t$ değeri anlamlıdır $(t=2,27 ; p<0,05)$. Buna karşın diğer parametrelerde hesaplanan ön test-son test ölçümleri arasında anlamlı bir fark bulunamamıştır. Anadolu Selçuklu Spor Kulübü U14 futbolcularının son test biceps ölçümlerinin ön teste kıyasla anlamlı düzeyde düşük olduğu görülmüştür. 
Tablo 3. Anadolu Selçuklu Spor Kulübündeki U16 takım sporcularının ön test-son test ölçümlerinin karşılaştırılması

\begin{tabular}{|c|c|c|c|c|c|c|}
\hline & \multicolumn{2}{|c|}{ Ön Test } & \multicolumn{2}{|c|}{ Son Test } & \multirow[b]{2}{*}{$T$} & \multirow[b]{2}{*}{$\mathbf{P}$} \\
\hline & Ortalama & Ss & Ortalama & Ss & & \\
\hline Biceps & 4,65 & 1,23 & 4,24 & 1,01 & 3,267 & ,003* \\
\hline Triceps & 9,37 & 2,90 & 8,62 & 2,54 & 1,882 & ,072 \\
\hline Subscapular & 8,46 & 1,67 & 8,61 & 1,51 &,- 745 & 463 \\
\hline Suprailiak & 6,34 & 1,73 & 6,23 & 1,57 & ,581 & ,566 \\
\hline Sırt Kuvveti & 68,73 & 18,31 & 66,46 & 21,66 & ,756 & ,457 \\
\hline Bacak Kuvveti & 37,90 & 8,69 & 34,31 & 9,39 & 1,565 & , 130 \\
\hline Pençe Kuvveti & 29,96 & 6,64 & 33,34 & 5,71 & $-4,444$ &, $000^{*}$ \\
\hline 30 M Sürat (Sn) & 4,53 & 0,33 & 4,79 & 0,42 & $-2,352$ &, $027^{*}$ \\
\hline $\begin{array}{l}\text { MaxVO2 } \\
\text { Mesafe }\end{array}$ & $\begin{array}{c}50,98 \\
1283,08\end{array}$ & $\begin{array}{c}2,82 \\
190,32\end{array}$ & $\begin{array}{c}50,76 \\
1195,77\end{array}$ & $\begin{array}{c}3,88 \\
220,04\end{array}$ & $\begin{array}{l}, 350 \\
2,263\end{array}$ & $\begin{array}{l}\text {,730 } \\
\text {,033* }\end{array}$ \\
\hline
\end{tabular}

Tablo 3.'e göre yapılan analiz sonucunda Anadolu Selçuklu Spor Kulübü U16 Futbol Takımı sporcularının ön test-son test ölçümleri üzerinde gerçekleştirilen analiz sonuçları görülmektedir. Analizlere göre Anadolu Selçuklu Spor Kulübü U16 takımı futbolcularının biceps, pençe kuvvet, $30 \mathrm{~m}$ sürat ve mesafe ön test-son test ölçümlerinde hesaplanan $t$ değeri anlamlı farkı ortaya koymuştur. Bu parametreler ayrıntılı olarak incelendiğinde pençe kuvveti ve 30 metre sürat testlerinde U16 futbolcular son testte anlamı düzeyde yüksek ortalamalar elde etmişlerdir. Buna karşın U16 takımı futbolcularının biceps ve Mesafe ise son test ölçümlerinin ön teste kıyasla anlamlı düzeyde düşük olduğu görülmüştür.

Tablo 4. Konyaspor Kulübündeki U14 takım sporcularının ön test-son test ölçümlerinin karşılaştırılması

\begin{tabular}{|c|c|c|c|c|c|c|}
\hline & \multicolumn{2}{|c|}{ Ön Test } & \multicolumn{2}{|c|}{ Son Test } & \multirow[b]{2}{*}{$\mathbf{T}$} & \multirow[b]{2}{*}{$\mathbf{P}$} \\
\hline & Ortalama & Ss & Ortalama & Ss & & \\
\hline Biceps & 5,39 & 1,04 & 4,97 & 1,90 & 1,446 & , 166 \\
\hline Triceps & 8,37 & 2,09 & 8,24 & 1,96 & ,524 & ,607 \\
\hline Subscapular & 7,03 & 1,10 & 7,58 & 2,08 & $-1,138$ & ,271 \\
\hline Suprailiak & 6,52 & 2,23 & 6,41 & 2,32 & 1,033 & ,316 \\
\hline Sırt Kuvveti & 59,13 & 10,64 & 58,58 & 13,82 & , 145 & ,886 \\
\hline Bacak Kuvveti & 35,81 & 8,11 & 39,00 & 13,20 & $-1,135$ & ,272 \\
\hline Pençe Kuvveti & 22,56 & 6,30 & 25,23 & 6,56 & $-2,986$ & ,008* \\
\hline 30 M Sürat (Sn) & 4,99 & 0,48 & 5,08 & 0,23 &,- 266 & ,794 \\
\hline $\begin{array}{l}\text { MaxVO2 } \\
\text { Mesafe }\end{array}$ & $\begin{array}{c}49,16 \\
1016,67\end{array}$ & $\begin{array}{c}5,98 \\
261,15\end{array}$ & $\begin{array}{c}50,29 \\
1165,88\end{array}$ & $\begin{array}{c}5,39 \\
293,83\end{array}$ & $\begin{array}{c}-, 752 \\
-1,806\end{array}$ & $\begin{array}{l}\text {, 463 } \\
, 090\end{array}$ \\
\hline
\end{tabular}


Tablo 4'e göre yapılan analiz sonucunda Konya Spor U14 Futbol Takımı sporcularının ön test-son test ölçümleri üzerinde gerçekleştirilen analiz sonuçları görülmektedir. Bağımlı örneklem t testi analizlere göre U14 takımı futbolcularının boy, kilo ve Pençe Kuvveti ön test-son test ölçümlerinde hesaplanan $t$ değerleri anlamlıdır. Bu parametreler ayrıntılı olarak incelendiğinde boy, kilo ve Pençe Kuvveti ölçümlerinde U14 takımı sporcuları son testte anlamı düzeyde yüksek ortalamalar elde etmişlerdir.

Tablo 5. Konyaspor Kulübündeki U16 takım sporcularının ön test-son test ölçümlerinin karşılaştııılması

\begin{tabular}{|c|c|c|c|c|c|c|}
\hline & \multicolumn{2}{|c|}{ Ön Test } & \multicolumn{2}{|c|}{ Son Test } & \multirow[b]{2}{*}{$\mathbf{T}$} & \multirow[b]{2}{*}{$\mathbf{P}$} \\
\hline & Ortalama & Ss & Ortalama & Ss & & \\
\hline Biceps & 5,77 & 1,52 & 5,22 & 1,53 & 3,199 &, $004^{*}$ \\
\hline Triceps & 8,88 & 2,13 & 9,12 & 2,25 &,- 920 & 368 \\
\hline Subscapular & 10,00 & 1,83 & 10,12 & 1,18 &,- 459 & 651 \\
\hline Suprailiak & 8,29 & 3,27 & 8,45 & 2,41 &,- 363 & ,720 \\
\hline Sırt Kuvveti & 73,78 & 14,60 & 71,16 & 14,68 & 995 & 331 \\
\hline Bacak Kuvveti & 39,11 & 9,41 & 43,07 & 18,59 & $-1,085$ & ,290 \\
\hline Pençe Kuvveti & 34,61 & 3,22 & 37,54 & 5,31 & $-3,805$ &, $001^{*}$ \\
\hline 30 M Sürat (Sn) & 4,88 & 0,26 & 4,80 & 0,47 & ,802 - & ,432 \\
\hline $\begin{array}{l}\text { MaxVO2 } \\
\text { Mesafe }\end{array}$ & $\begin{array}{c}50,67 \\
1524,09\end{array}$ & $\begin{array}{c}4,61 \\
260,41\end{array}$ & $\begin{array}{c}53,00 \\
1589,09\end{array}$ & $\begin{array}{c}3,81 \\
289,22\end{array}$ & $\begin{array}{l}-2,473 \\
-1,836\end{array}$ & $\begin{array}{l}, 022^{*} \\
, 080\end{array}$ \\
\hline
\end{tabular}

Tablo 5'e göre yapılan analiz sonucunda Konya Spor U16 Futbol Takımı sporcularının ön test-son test ölçümleri üzerinde gerçekleştirilen analiz sonuçları görülmektedir. Bağımlı örneklem $\mathrm{t}$ testi analizlere göre U16 takımı futbolcularının boy, kilo, biceps, pençe kuvveti ve MaxVO2 ön test-son test ölçümlerinde hesaplanan t değerleri anlamlıdır. Bu parametreler ayrıntılı olarak incelendiğinde boy, kilo, pençe kuvveti ve maxVO2 testlerinde U16 futbolcular son testte anlamı düzeyde yüksek ortalamalar elde etmişlerdir. Buna karşın U16 takımı futbolcularının biceps'te ise son test ölçümlerinin ön teste kıyasla anlamlı düzeyde düşük olduğu görülmüştür. 
Tablo 6. Konyaspor ve Anadolu Selçuklu Spor U14 - U16 futbol takımlarında bulunan sporcuların ön test ölçümlerinin karşılaştırıması

\begin{tabular}{lcccccc}
\hline & Takım & N & Ortalama & Ss & t & P \\
\hline Boy & Konya Spor & 40 & 1,67 & 0,10 & 0,65 & 0,52 \\
Kilo & Anadolu Selçuklu & 45 & 1,65 & 0,11 & & \\
& Konya Spor & 40 & 59,51 & 11,70 & 1,68 & 0,10 \\
Biceps & Anadolu Selçuklu & 45 & 55,55 & 10,04 & & \\
& Konya Spor & 40 & 5,60 & 1,32 & 1,44 & 0,15 \\
Triceps & Anadolu Selçuklu & 45 & 5,16 & 1,48 & & \\
& $\quad$ Konya Spor & 40 & 8,65 & 2,10 & $-1,75$ & 0,08 \\
Subscapular & Anadolu Selçuklu & 45 & 9,61 & 2,84 & $-1,78$ & 0,08 \\
& $\quad$ Konya Spor & 40 & 8,67 & 2,14 & 1,13 & 0,26 \\
Suprailiak & Anadolu Selçuklu & 45 & 8,18 & 1,81 & & \\
& Konya Spor & 40 & 7,50 & 2,95 & 1,73 & 0,09 \\
Sırt Kuvveti & Anadolu Selçuklu & 45 & 6,50 & 2,35 & & \\
& $\quad$ Konya Spor & 40 & 67,19 & 14,78 & 1,75 & 0,08 \\
Bacak Kuvveti & Anadolu Selçuklu & 45 & 60,77 & 18,48 & & \\
& Konya Spor & 40 & 37,63 & 8,90 & 1,70 & 0,09 \\
Pençe Kuvveti & Anadolu Selçuklu & 45 & 34,38 & 8,74 & & \\
\multirow{2}{*}{ 30 M Sürat Testi } & Konya Spor & 40 & 29,19 & 7,73 & 1,56 & 0,12 \\
& Anadolu Selçuklu & 45 & 26,60 & 7,53 & & \\
MaxvO2 & Konya Spor & 40 & 4,93 & 0,37 & 1,81 & 0,07 \\
& Anadolu Selçuklu & 45 & 4,77 & 0,44 & & \\
Mesafe & Konya Spor & 39 & 50,01 & 5,23 & 1,68 & 0,10 \\
& Anadolu Selçuklu & 45 & 48,17 & 4,86 & & \\
& Konya Spor & 40 & 1295,75 & 362,77 & 1,44 & 0,15 \\
& Anadolu Selçuklu & 45 & 1204,00 & 211,87 & & \\
\hline
\end{tabular}

$$
(p<0,05)
$$

Tablo 6'ya göre yapılan karşılaştırma sonucunda araştırmanın başlangııında Konyaspor ve Anadolu Selçuklu U16 spor takımlarında bulunan sporcuların ön test boy, kilo, sırt kuvveti, pençe kuvveti, biceps, triceps, subscapular, Suprailiak, bacak Kuvveti, mesafe, 30 M Sürat Testi ve MaxVO2 ölçümlerine ilişkin bağımsız örneklem $\mathrm{t}$ testi bulguları görülmektedir. Analiz sonuçlarına göre bu parametrelerde iki takımın ön test ölçümleri arasında anlamlı bir fark yoktur $(p>0,05)$. Ağustos ayında gerçekleştirilen ön test ölçümlerinde takımların birbirlerine denk bir dağııma sahip olduğu görülmektedir. 
Tablo 7. Konyaspor ve Anadolu Selçuklu Spor futbol takımlarında oynayan sporcuların son test ölçümlerinin karşılaştırılması

\begin{tabular}{|c|c|c|c|c|c|c|}
\hline & Takım & $\mathbf{N}$ & Ortalama & Ss & $t$ & $\mathbf{P}$ \\
\hline \multirow[t]{2}{*}{ Boy } & Konya Spor & 40 & 1,70 & 0,09 & $-0,03$ & 0,97 \\
\hline & Anadolu Selçuklu & 44 & 1,70 & 0,22 & & \\
\hline \multirow[t]{2}{*}{ Kilo } & Konya Spor & 40 & 62,78 & 11,64 & 3,88 & $0,00^{*}$ \\
\hline & Anadolu Selçuklu & 44 & 53,75 & 9,70 & & \\
\hline \multirow[t]{2}{*}{ Biceps } & Konya Spor & 40 & 5,11 & 1,69 & 1,51 & 0,13 \\
\hline & Anadolu Selçuklu & 45 & 4,58 & 1,52 & & \\
\hline \multirow[t]{2}{*}{ Triceps } & Konya Spor & 40 & 8,73 & 2,15 & $-0,60$ & 0,55 \\
\hline & Anadolu Selçuklu & 45 & 9,06 & 2,85 & & \\
\hline \multirow[t]{2}{*}{ Subscapular } & Konya Spor & 40 & 8,98 & 2,07 & 2,24 & $0,03^{*}$ \\
\hline & Anadolu Selçuklu & 45 & 8,02 & 1,85 & & \\
\hline \multirow[t]{2}{*}{ Suprailiak } & Konya Spor & 40 & 7,53 & 2,56 & 1,74 & 0,09 \\
\hline & Anadolu Selçuklu & 45 & 6,58 & 2,47 & & \\
\hline \multirow[t]{2}{*}{ Sırt Kuvveti } & Konya Spor & 40 & 65,50 & 15,47 & 1,86 & 0,07 \\
\hline & Anadolu Selçuklu & 45 & 57,88 & 21,32 & & \\
\hline \multirow[t]{2}{*}{ Bacak Kuvveti } & Konya Spor & 40 & 41,24 & 16,32 & 3,61 & $0,00^{*}$ \\
\hline & Anadolu Selçuklu & 45 & 31,19 & 8,59 & & \\
\hline \multirow[t]{2}{*}{ Pençe Kuvveti } & Konya Spor & 40 & 32,00 & 8,51 & $-0,52$ & 0,60 \\
\hline & Anadolu Selçuklu & 45 & 35,83 & 45,78 & & \\
\hline \multirow[t]{2}{*}{30 Metre Sürat Testi } & Konya Spor & 39 & 4,92 & 0,40 & $-0,01$ & 0,99 \\
\hline & Anadolu Selçuklu & 45 & 4,93 & 0,40 & & \\
\hline \multirow[t]{2}{*}{ MaxVO2 } & Konya Spor & 39 & 51,82 & 4,70 & 3,48 & $0,00^{*}$ \\
\hline & Anadolu Selçuklu & 45 & 47,98 & 5,33 & & \\
\hline \multirow[t]{2}{*}{ Mesafe } & Konya Spor & 39 & 1404,62 & 357,46 & 3,53 & $0,00^{*}$ \\
\hline & Anadolu Selçuklu & 45 & 1174,89 & 232,60 & & \\
\hline
\end{tabular}

$(p<0,05)$

Tablo 7'ye göre yapılan karşılaştırma sonucunda araştırmanın Nisan ayında gerçekleştirilen son test ölçümlerinde Konyaspor ve Anadolu Selçuklu U14-U16 spor takımlarında bulunan sporcuların sırt kuvveti, pençe kuvveti ve mesafe ölçümlerine ilişkin karşılaştırma bulguları görülmektedir. Bağımsız örneklem $t$ testi ile gerçekleştirilen analizlere göre son test boy, biceps, triceps, suprailiak, sırt kuvveti, pençe kuvveti ve $30 \mathrm{mt}$ sürat son test ölçümlerinde anlamlı bir fark bulunamamıştır $(p>0,05)$. Buna karşın kilo, mesafe subscapular, bacak kuvveti ve maxVO2 ölçümlerinde anlamlı bir fark söz konusudur $(p<0,05)$. Son test ölçümlerin ortalamalarına göre Konyasporlu futbolcuların Anadolu Selçuklu Spor takımında oynayan akranlarına kıyasla daha yüksek kilo, subscapular, suprailiak, bacak kuvveti ve MaxVO2 ölçümleri elde ettikleri görülmüştür.

\section{Tartışma ve Sonuç}

$\mathrm{Bu}$ çalışmada Konyaspor ve Anadolu Selçuklu Spor U14 - U16 futbol takımlarında en az 2 yıldır futbol oynayan 14-16 yaş aralığındaki sporcuların bir futbol sezonundaki bazı fizyolojik ve motorik özelikleri karşılaştırmalı olarak incelenmiştir. 
U14 takımlarında gerçekleştirilen ön test-son test karşılaştırmalarında Anadolu Selçuklu Spor Kulübü U14 futbolcularının sadece biceps ön test-son test ölçümlerinde hesaplanan t değeri anlamlıdır. Abe ve ark., (1999)' a göre güçlü biceps kaslarına sahip olmak, hokey, badminton, beyzbol, futbol ve daha birçok spor dalında sporcular için önemli bir avantaj sağlamaktadır. Futbolda top yakalamak, atmak ve rakiple omuz omuza mücadelede güçlü biceps kasları önemli rol oynamaktadır. Abe ve ark., (1999) futbol müsabakaları açısından futbol mücadelesine etkin katılım için biceps açısından eşit ve yeterli güç ve esnekliğin korunmasını önerir. Bu kapsamda Anadolu Selçuklu Spor U14 takımındaki sporcularına uygulanan antrenman programıyla güçlü bir biceps skoruna ulaştıkları görülmektedir.

Anadolu Selçuklu Spor Kulübü U16 Futbol Takımı sporcularının ölçümleri üzerinde gerçekleştirilen analizlere göre biceps, pençe kuvveti, 30 M Sürat ve mesafe ön test-son test ölçümlerinde anlamlı farkı bir fark söz konusudur. Anadolu Selçuklu Spor Kulübü U16 Futbol Takımı sporcuları pençe kuvveti ve 30 metre sürat testlerinde son testte anlamı düzeyde yüksek ortalamalar elde etmişlerdir. biceps ve mesafe ise son test ölçümlerde anlamlı düzeyde düşüşler olduğu görülmüştür.

Konya Spor U14 Futbol Takımı sporcularının ön test-son test ölçümleri üzerinde gerçekleştirilen analiz sonuçları göre boy, kilo ve pençe kuvveti ölçümlerinde son test lehine anlamlı farklar gözlenmiştir.

Konya Spor U16 Futbol Takımı sporcularının ön test-son test ölçümleri üzerinde gerçekleştirilen analizlere göre boy, kilo, biceps, pençe kuvvet ve maxVO2 ön test-son test ölçümlerinde anlamlı farklar gözlenmiştir. Konyasporlu U16 futbolcuların boy, kilo, pençe kuvveti ve maxVO2 ölçümlerinde son testte anlamı düzeyde yüksek puanlar elde ettiği görülmüştür. Buna karşı biceps'te ise son test ölçümlerinde anlamlı düzeyde düşüşler olduğu görülmüştür.

Araştırma bulgularına göre her iki U16 takımın araştırma parametrelerinde benzer bir değişimin olduğu görülmektedir. Ayrıca U16 sporcularının araştırma parametrelerinde son testte ortaya çıkan bulgular U14 takımlarından oldukça farklılık göstermektedir.

Brown ve ark., (1986) ve Christou ve arkadaşlarına (2006) göre futbolda sporcuların performanslarını geliştirmek için amaçlı ve kompleks antrenman süreçlerinin aktif olarak gerçekleşmesi önem arz etmektedir. Özellikle futbolda konsantrik kuvvet ve sürat antrenmanıyla sporcuların gerek maç esnasında gerekse de hazırlıklarında sürat, çeviklik, kuvvet, patlayıcı güç performanslarının maksimum 
düzeye çıkarılması amaçlanmaktadır. Bu uygulamalar hem sporcuların bireysel olarak hem de takımların oyun performansını birinci derecede etkilemektedir. Buchheit ve ark., (2010) yaptıkları çalışmada yüksek seviyeli genç futbolcularda tekrarlayan sprint dizilerinin (RSS) oluşumunu ve doğasını, yaş, oyun pozisyonu ve oyun zamanının bir fonksiyonu olarak incelemişlerdir. Araştırma bulgularına göre tekrarlanan sprint yeteneğinin çok önemli olduğunu sorgulayarak futbol performansının oyuncuların fiziksel unsurların gelişmiş olmasının önemli olduğunu vurgulamıştır. Bu yönüyle Anadolu Selçuklu Spor U14 takımında sadece biceps ölçümlerinde diğer taraftan Konya Spor takımında ise pençe kuvvet son test ölçümlerinde artış olması her iki takımda farklı antrenman programlarının ve süreçlerinin uygulandığına işaret etmektedir.

Biçer ve Akkuş (2005) Konya Amatör Futbol takımları ve Selçuk Üniversitesi Futbol takımlarına yaptığı testlerde pençe kuvveti, ortalama değeri hazırlık

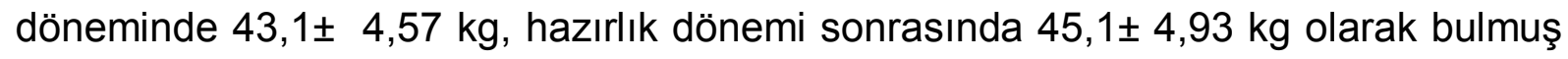
ve istatistiksel açıdan 0,01düzeyinde farklılıklar bulmuştur. $50 \mathrm{~m}$ sürat ortalama değerlerini hazırlık dönemi öncesi $6,34 \pm 0,20 \mathrm{sn}$, hazırlık dönemi sonrası 6,26 0,19 sn olarak bulmuş ve istatistiksel açıdan 0,01 düzeyinde anlamlı farklılık gözlemlemiştir.

Yavuz (1997) yaptığı çalışmada 16-18 yaş aralığında spor yapan ve spor yapmayan gençler arasında vücut yağ oranı ve aerobik gücün ilişkisi çalışmasında boy, ağırlık ve vücut yağ yüzdesi arsında istatistiki olarak fark bulunmamıştır. Fakat aerobik gücü ölçülmesinde kullanılan Cooper testi sonuçlarında istatistiki anlamda fark bulunmuştur.

Nikolaidis ve arkadaşları (2016) 20 m sprint performansı üzerindeki etkisini incelemek; ve ikincisi, futbolcularda yaşa göre $20 \mathrm{~m}$ sprint performansı için normatif veri oluşturmak için yaptıkları çalışmada sporcuların sürat özellikleri karşılaştırmalı olarak incelemişlerdir. Analizlere göre sprint açısından yıllık yaş grupları arasında anlamlı farklııklar olduğunu ortaya çıkmıştır. Özet olarak, futbolcuların hız yetenekleri, 15 yaşına kadar yapılan antrenman programı çerçevesinde geliştiğini buldular. Öte yandan, diğer yaş grupları U16 ile U35 arasında, $20 \mathrm{~m}$ sürat koşusu üzerinde hızda önemli bir fark bulunmadığını belirtmektedir.

Karahan (2016) yaptığı çalışmada U-15, U-17 ve U-19 olarak sporcuları üç kronolojik yaş grubunda sınıflandırımışıı. Fiziksel performans verileri, U-15 grubunun 10 ve 20 metreden daha yavaş olma eğiliminde olduğunu ve en zayıf 
çevikliğe ve anaerobik güce sahip olduğunu göstermiştir. Patlayıcı güç hariç, U-17'nin performans değerleri U-19'dan düşük olduğunu $(p<0.05)$. Sonuç olarak, üç grup arasında anlamlı farklııılar olduğunu belirtmiştir.

Genç (2015) yaptığı çalışmada 10-14 yaş grubu 24 çocuk üzerinde yaptığı aerobik kapasite, anaerobik güç, kuvvet, sürat, esneklik ve teknik özelliklerinin geliştirilmesi için yaptığı 2 haftalık araştırmada maxVO2, bir pas ile top sürme değerlerinde, $10 \mathrm{~m}$ sprint, ayak ve diz saydırma, pas verme ve dripling değerlerinde anlamlı artış meydana gelmiştir.

Göksu (2004) yılında 20 Türk elit bayan sporcularına 3 adet fiziksel ve fizyolojik parametrelerdeki değişiklikleri incelediği çalışmasında; tüm verilerde istatistiksel olarak anlamlı farklar bulmuştur. Oluşan bu farkların nedenlerini yapılan maç ve antrenman programlarının sporculara olan uygunluğu, antrenmanların sporcu üzerinde verimli etkisi, antrenmanların sporculara devamlıığı ve disiplinli sporcu yaşamlarının olmasını göstermiştir.

$\mathrm{Bu}$ bağlamda özellikle alt yapı antrenman süreçlerinde sporcuların yaş ve düzeylerine uygun yüklenmelerin yapılmasının sporcuların gelişim ve verimliliklerini doğrudan etkileyeceğini düşünmekteyiz. İki farklı futbol takımının iki farkı alt yaş kategorisinde mücadele eden sporcularında farklı antrenman değerleri elde ettikleri yaptığımız çalışmada ortaya çıkmaktadır. Buradan yola çıkarak alt yaş kategorilerinde antrenmanların sporcuların performans gelişimine katkı sağlayıp sağlamadığı, beklenen fizyolojik parametre ve etkileri ortaya çıkartıp çıkartmadığının yapılacak benzeri çalışmalar ile saptanabileceğini ve bu suretle genç sporcuların gelişimine katkı sağlayacak bilimsel temelde ve veriye dayalı çok yönlü ve karma antrenman programları uygulanarak fizyolojik ve motorik özeliklerin gelişiminin sağlanabileceğini düşünmekteyiz. Ayrıca sporculara kendi fizyolojik ve motorik özelikleri ve bunun değişim ölçümleriyle ilgili geri bildirimlerde bulunularak profesyonel gelişimlerine katkıda bulunulabilir ve sporcuların fizyolojik, motorik özellikleri ve müsabaka performanslarıyla ilgili verilerin sağıklı bir şekilde kayıtları tutularak antrenman programlarında kullanılması sağlanabilir.

\section{Kaynaklar}

Abe T, Brown, J, \& Brechue, W. (1999). Architectural characteristics of muscle in black and white college football players. Medicine and Science in Sports and Exercise, 31(10):1448-1452 
Biçer, M. ve Akkuş, H. (2005). Futbolcularda hazırlık dönemi çalışmalarının bazı fiziksel ve fizyolojik parametreler üzerine etkisi. Selçuk Üniversitesi Beden Eğitimi ve Spor Bilim Dergisi, 7(1).

Brown, M., Mayhew, Y., \& Boleach, L. (1986). Effect of plyometric training on vertical jump performance in high school basketball players. The Journal of Sports Medicine and Physical Fitness:26 p.1-3.

Buchheit, M., Mendez-Villanueva, A., Simpson, B. M., \& Bourdon, P. C. (2010). Repeated-sprint sequences during youth soccer matches. International journal of sports medicine, 31(10), 709-716.

Christou, M., Smilios, I., Sotiropoulos, K., Volaklis, K., Pilianidis, T., \& Tokmakidis, S. P. (2006). Effects of resistance training on the physical capacities of adolescent soccer players. The Journal of Strength \& Conditioning Research, 20(4), 783791.

Genç, H. (2015). Futbolda Farklı Antrenman Metotlarının Çocukların Bazı Fiziksel Fizyolojik ve Teknik Kapasiteleri Üzerine Etkilerinin Karşıllaştırılması, Doktora Tezi, Gazi Üniversitesi Sağlık Bilimleri Enstitüsü, Ankara.

Göksu, Ö. (2004). Türk Elit Bayan Futbol Oyuncularının Bir Sezona Ait Fiziksel Fizyolojik Parametrelerindeki Değişikliklerin İncelenmesi, Doktora Tezi, Gazi Üniversitesi Sağık Bilimleri Enstitüsü, Ankara.

Karahan, M. (2016). Age-related Physical Performance Differences in Male Soccer Players, The Anthropologist, 24:3, 724-729.

Kılıç, C. (2007). İlköğretim birinci kademe öğrencilerinin bazı fiziksel uygunluk seviyelerinin karşılaştırılması. Yüksek Lisans Tezi, Gazi Üniversitesi Sağlık Bilimleri Enstitüsü, Ankara.

Koç, H. (2010). Comparisson of some physical and motor features of footballers playing at winnig team in Professional and amateur league. 12, 150-156.

Nikolaidis, P. T., Knechtle, B., Clemente, F., \& Torres-Luque, G. (2016). Reference values for the sprint performance in male football players aged from 9-35 years. Biomedical Human Kinetics, 8(1), 103-112.

Taşkın, C. (2015). Futbolcu çocuklarda seçilmiş motorik özellikler arasındaki ilişkinin incelenmesi. 6, 102.

Yavuz, H. (1997). 16-18 Yaş Futbolcularda ve Spor Yapmayan Genç Erkeklerde Vücut Yağ Oranı ile Aerobik Gücün İlişkisi, Yüksek Lisans Tezi, Selçuk Üniversitesi Sağlık Bilimleri Enstitüsü, Konya. 